\title{
EL ANÁLISIS EXISTENCIAL DE BINSWANGER Y LA ANTROPOLOGía ORTEGUIANA, PUNTOS DE ENCUENTRO
}

\author{
BINSWANGER'S DASEINANALYSE AND \\ ORTEGUIAN ANTHROPOLOGY, MEETING POINTS
}

\author{
Jorge Montesó Ventura* \\ Centre d'Estudis Antropològics ACAF
}

\begin{abstract}
Resumen: En la aplicación de la Analítica Existencial heideggeriana al campo de la psiquiatría, Binswanger se vio con la necesidad de trascender ciertos aspectos de su pensamiento encaminando su planteamiento ontológico a una tematización de calado antropológico. Esta interpretaría la "existencia" como la existencia de cada sujeto particular en su mundo vivido. Teniendo presente que, para Binswanger, el mundo contemplaba innegociablemente al "otro", el modelo de ser-en-el-mundo se ampliaría a ser-en-el-mundo-con-otros, por lo que la noción de Sorge, orientada hacia uno mismo, se vería igualmente ampliada a la de Liebe, implicando ese amor a la alteridad. Estas progresiones, como veremos en el artículo, despiertan no pocos acercamientos al pensamiento orteguiano. Así, advertimos la proximidad a la idea de "vida"; a sus nociones antropológicas e intentos de catalogación sociológica; la idea de "preocupación" como cuidado, que contempla a la circunstancia como parte de "mi vida" y, en ella, necesariamente al otro como prójimo. Estas y otras conexiones entre ambos autores será lo que analicemos en el presente artículo.
\end{abstract}

Palabras Clave: Existencia, vida, Liebe, preocupación, análisis existencial.

* Departamento de Antropología filosófica. E-mail: jordimonteso@gmail.com 
АвSTRACT: In the application of Heidegger's Daseinanalytic to the field of psychiatry, Binswanger saw the need to transcend some aspects of his thinking by redirecting his ontological approach towards an anthropological line. In this way, we should interpret "existence" as the existence of a particular subject in his life-world. Knowing that, to Binswanger, the world always implies the "other", the model of being-in-the-world would be extended to being-in-the-world-with-others; so the notion of Sorge, oriented toward oneself, would be extended to Liebe, denoting love of otherness. As we will see in this article, these progressions awaken several approaches to Ortega's thinking. We can appreciate the proximity to the idea of "life", and to his anthropological notions and attempts to make a sociological catalogue. We can also see the idea of preoccupation as care, which implies the circumstance as part of "my life", in which the other exists as a fellowman. We will analyse, in this article, these and others connections between both authors.

Keywords: existence, live, Liebe, preoccupation, Daseinanalysis

\section{Introducción}

Cuando se habla de Ludwig Binswanger es frecuente rescatar de la memoria su papel en la gestación de la psicología existencial, una de las emergentes corrientes psicológicas que arraigaron en Europa en la primera mitad de siglo XX cuando una intensa efervescencia epistemológica hizo que esta se encontrase, como bien dijese Ortega, "mudando de dioses y, por lo tanto, sin dioses" (OC, VII, 439). El subjetivismo se agotaba por aquel entonces al mismo ritmo que su fundamento racionalista. Frente a tal extenuación, las alternativas para dar viabilidad a un sistema de psicología nuevo emergían desde los más diversos ámbitos. En Leipzig, por ejemplo, irrumpía Wundt con su estructuralismo mientras Külpe abanderaba, en Wurzburgo, una opositada desafección a este; Freud, por su parte, desarrollaba su psicoanálisis mientras Husserl publicaba sus Investigaciones Lógicas inaugurando el método fenomenológico; con Dewey llegaba a Europa el funcionalismo de James mientras que, en 1913, aparecían los fundamentos de la escuela conductista y de la Teoría de la forma. En semejante agitación fue en la que Binswanger, un joven médico familiarizado por linaje con los ambientes terapéuticos ${ }^{1}$, inició sus andanzas en el mundo de la psiquiatría.

${ }^{1}$ El padre de Binswanger fue regente de la clínica Bellevue, en Kreuzlingen, fundada por su abuelo, que él mismo dirigiría hasta 1956 para cederla a su hijo Wolfgang (cfr. VILLEGAS, 
Así, se doctoró con Jung realizando su internado con Bleuler². Gran parte de su formación se entabló en el seno del marco psicoanalista, hasta el punto de forjar una larga amistad con el propio Freud ${ }^{3}$. No obstante, pese a tan cercano vínculo -que nunca cedería, al menos en su facción terapéutica-, no tardaría en advertir importantes carencias en el horizonte de comprensión humana del psicoanálisis que, por su acérrimo biologicismo, pronto le resultaría demasiado limitado y restrictivo. Para el suizo, la escuela psicoanalítica resultó estar demasiado aferrada a la idea del homo-natura como posibilidad única para aprehender al ser humano más allá del subjetivismo. Es más, no solo era biológica en exceso sino también fundamentalmente pansexual, lo que limitaba, a ojos del suizo, demasiado su visión pues, para alcanzar lo que el ser humano es, a Binswanger le faltaba el aspecto más vital e histórico del hombre, lo biográfico.

Así, no demoró su emancipación del psicoanálisis y, dado el tipo de asuntos que le inquietaban, la filosofía se presentó como el terreno más fértil para anidar sus consideraciones. Como muchos de sus coetáneos, quizá tuvo la misma buena suerte $^{4}$ cuando topó con la fenomenología. El encuentro con Husserl, después con Scheler y Brentano, especialmente con Heidegger ${ }^{5}$, marcó un antes y un después en su pensamiento. La fenomenología supuso, para el psiquiatra suizo, una inmejorable herramienta de superación del reduccionismo psicoanalítico, pero no entendiendo superación como rotura o abandono, para Binswanger la superación tuvo más que ver con la idea del Aufhebung hegeliano de absorción. Cuando hallase a la fenomenología, indica Villegas $(1981,10)$, "los temas de Psicoanálisis y Fenomenología se irán entrecruzando”, se fundirán la concepción fenomenológica del hombre con el método de intervención psicoanalítico, lo

M. (1981). "Ludwig Binswanger: En el centenario de su nacimiento". Anuario de Psicología. Núm. 24/1, p. 5).

${ }^{2}$ Cfr. BOEREE, C. G. (2005). "Teorías de la personalidad. Ludwig Binswanger (18811966)". Teoría de la Personalidad: una selección de los mejores autores del siglo XX. Sto. Domingo: UNIBÉ, pp. 1-12. Recuperado el 4 de marzo de 2015 de http://www.psicologia-online. com/ebooks/personalidad/binswanger.htm

${ }^{3}$ Cfr. FREUD, S. y BINSWANGER, L. (1995). Sigmund Freud-Ludwig Binswanger. Correspondance 1908-1938. En FICHTNER, G. (ed.). Paris: Calman-Levy. También en Psychoanalytiv Electronic Publishing. Recuperado el 4 de marzo de 2015 de http://www.pep-web.org/ document.php?id=zbk.050.0000a

${ }^{4}$ Ortega, en su Prólogo para alemanes describiría su encuentro con la fenomenología diciendo que "no fue para nosotros una filosofía: fue... una buena suerte" (OC, IX, 125).

${ }^{5}$ Villegas destaca la amistad que Binswanger mantuvo con fenomenólogos como Pfänder, Scheler y Husserl, Buber, el mismo Heidegger e incluso con Ortega y Gasset (cfr. VILLEGAS, M. op. cit., p. 6). 
concreto con lo universal, lo biográfico con lo biológico. La fenomenología, pues, daría a Binswanger el necesario amarre en las cosas mismas y a la vida individual, mundana, que tanto echó de menos en el psicoanálisis. Es más, con la inmersión ontológica de la fenomenología en Heidegger -que él vivió muy activamente-, conseguiría, precisamente, esa amalgama de lo biológico que ya portaba consigo con una comprensión más existencial, más biográfica del ser humano al trascender la vieja dualidad sujeto-objeto bajo la noción de ser-en-el-mundo.

Así, Binswanger pronto dedicó todo su empeño en ahondar en el estudio de la Daseinanalytik heideggeriana ${ }^{6}$, una analítica de aire existencial donde el suizo hallaría el faro de sus futuras inquisiciones. Estas se dirigieron frontalmente a establecer, por un lado, una aplicación del Daseinanalytik -con su horizonte de comprensión humano- a la psiquiatría en su conjunto, intentando dotar a dicha disciplina de un nuevo fundamento, pues el actual carecía de valor heurístico ${ }^{7}$. A su vez, por su condición de psiquiatra terapeuta, aspiró a una matriz aún más profunda y radical: alcanzar la estructura misma de la personalidad del ser humano para, después, analizarla y describirla. Así, tras los pasos fenomenológicos -husserlianos- y abriéndose a la vertiente existencial de Heidegger, Binswanger estableció los puntos primordiales del que sería su Análisis Existencial -su Daseinanalyse-, una revisión de la Analítica heideggeriana con aspiraciones menos ontológicas y más descriptivas debido a su necesidad terapéutica, lo que le conduciría a alojarse en un espacio de comprensión más antropológico que el de Heidegger, yendo más allá -mejor dicho, "más acá"- de este; mudando su analítica ontológica en un análisis antropológico; pretendiendo alcanzar daciones del ser mucho más concretas y descriptibles, más pragmáticas, esto es, los modos particulares de existencia en y por sí mismos.

Debido, pues, a tal pretensión, Binswanger no tardaría en distanciarse también del planteamiento heideggeriano, una distancia que se enfatizaría con la superación de la idea del Sorge al asentar -con la idea de Liebe- en un concepto

\footnotetext{
${ }^{6}$ En HEIDEGGER, M. (2009). Ser y tiempo. Madrid: Ed. Trotta; cfr. (1929) y "De la esencia del fundamento". Ser, Verdad y Fundamento. PsiKolibro. Recuperado el 4 de marzo de 2015. http://es.scribd.com/doc/23604852/Martin-Heidegger-Ser-Verdad-yFundamento\#scribd

${ }^{7}$ Cfr. FERRO BAYONA, J. (2001). "Filosofía y Psicología en el Análisis Existencial de Ludwig Binswanger”. Psicología desde el Caribe. Universidad del Norte. Núm. 7, p. 49. Valga decir que, en este empeño por fundamentar o renovar la fundamentación de la psicología como disciplina, coincidiría con algunos de sus coetáneos como el propio Ortega y su Sistema de la Psicología.
} 
que extendía la estructura original de ser-en-el-mundo a otro tipo de estructura, la de ser-más-allá-del-mundo como modo de ser-con-el-otro, a un "nosotros", una forma que representaba, como veremos, el modelo de autenticidad humano. Así, afirma Villegas que Binswanger:

no seguirá estrictamente a Heidegger, sino que de alguna manera lo trascenderá: "no se trata de una simple diferencia de opinión, sino de una diferencia ontológica" [...]. El punto fundamental de diferenciación es la sustitución de la cura (Sorge) por el amor (Villegas, 1981, 11).

Yace aquí el motivo del presente artículo, en el efecto que se desprende de que, con el desarraigo heideggeriano, Binswanger se fuese acercando, con toda probabilidad involuntaria e inconscientemente, a ciertas ideas o conceptos de abolengo orteguiano. Lo veremos con la idea de "existencia" en sentido concreto e individual, que nos acerca mucho a la idea de "vida" defendida por el madrileño; lo veremos también con la muda del Sorge al Liebe que, por ese carácter intersubjetivo y concreto, se aproximará mucho a la idea de "preocupación" orteguiana hasta posibilitar - pese a las distancias- una mejor articulación entre su concepto del cuidado y el Sorge heideggeriano. Con todo, repasaremos, y reivindicaremos, el intento binswangeriano de trascender a Heidegger al tiempo que, dado el acercamiento realizado a Ortega, trataremos de esclarecer o aportar argumentos a favor de la originalidad y pragmatismo del ideario orteguiano en este campo frente al del germano el cual, por sus desiguales circunstancias, siempre ha lobreguecido en reconocimiento, hecho que, en nuestra modesta opinión, y así lo intentaremos evidenciar, no parece adecuado dadas sus diferentes pretensiones.

\section{El Análisis existencial, de la Analítica existencial heideggeriana a la antropología orteguiana}

La psicología existencial, bajo el prisma de Binswanger, se centró en la labor de aplicar al terreno de la psicología terapéutica los postulados fenomenológicoexistenciales. El fin no era otro que posibilitar un acercamiento a los distintos trastornos mentales -incluidos los conceptos mismos de salud y enfermedad- 
mediante vías alternativas al habitual juicio categorial y cuantitativo ${ }^{8}$ que dominaba la psiquiatría formal. Fue un intento, con mayor o menor fortuna-pues muchos son los críticos que ven en esta corriente un frustrado método terapéutico sin menosprecio de sus resultados descriptivos y heurísticos' - de abrir una grieta en el establishment psiquiátrico con el fin de posibilitar diagnósticos e intervenciones basadas en un método más descriptivo, más holístico y que, sin juicios apriorísticos, entendiese la enfermedad dentro de la propia existencia del sujeto y no como algo excepcional a la misma. Para ello, establecieron en el concepto de "existencia" su piedra de toque o eje de comprensión de lo humano, desplazando, muy al estilo heideggeriano, la noción de "conciencia”. Así, para los psicólogos existencialistas, lo principal sería la existencia, en el caso de Binswanger, la existencia de cada cual de un modo concreto, pues la intención terapéutica le obligaba a superar las nociones abstractas, ontológicas, para establecer modos efectivos de abordar ese ser-en-el-mundo.

Para Heidegger, el ser, en cuanto humano, se daba como un ser abierto (Lichtung) al mundo, implicado en el mundo, interesado por el mundo. Heidegger -como, por cierto, también hiciese Ortega por diferentes vías y con cierta anterioridad mediante su idea de vida ${ }^{10}$ - rompía con la concepción dual de sujeto-objeto para alcanzar una determinada unidad bajo el concepto de "existencia" (Existenz) donde, como apunta Villegas $(1981,15)$, "yo-mismo y mundo, son conceptos recíprocos". El pensador germano, en Sein und Zeit, revelaba la estructura trascendental de la existencia en tanto concebía a esta como ser-en-elmundo, abriendo el horizonte de comprensión de lo humano al terreno histórico, a su mundanidad y, por tanto, posibilitando el entendimiento de su facticidad. En ella, en la facticidad, hallamos el fundamento de la existencia, el modo de ser específico de la vida. La vida, en Heidegger, no es nada que esté ahí entre otros, sino que existe, se ocupa y se pre-ocupa, por ello apela a la posibilidad de ser, a la pre-tensión de ser aquello que aún no se es, a saber, un proyecto. Aquí

\footnotetext{
${ }^{8}$ Cfr. DÖRR, O. (2008). "Los trastornos de personalidad desde una perspectiva fenomenológica". Actas Españolas de Psiquiatría. Núm. 36/1, pp. 10-19. Recuperado el 4 de marzo de 2015 de http://actaspsiquiatria.es/repositorio/9/49/ESP/9-49-ESP-10-19-774914.pdf

9 Afirma Solé: "En ningún caso impugnamos los valiosos hallazgos psicopatológicos [...]. Sólo queremos constatar su confesa permanencia en una filosofía de la conciencia de reconocida esterilidad terapéutica, desde Binswanger y Minkowski hasta la actualidad [...]. Por el momento la tarea fenomenológica se ha ceñido al análisis exhaustivo, a la exploración detallada y a la consiguiente reelaboración descriptivo-constructiv(ist)a” (Solé, 2011, 654).

10 “'Vivir es, de cierto, tratar con el mundo, dirigirse a él, actuar en él, ocuparse de él'. ¿De quién es esto? ¿De Heidegger, en 1927, o publicado por mí con fecha de diciembre de 1924” (OC, V, 128n).
} 
encuentra a Ortega, para quien la vida significa "la inexorable forzosidad de realizar el proyecto de existencia que cada cual es [...], es nuestro auténtico ser, es nuestro destino"(OC, V, 124). Así decimos que el sujeto es existiendo. Heidegger, grosso modo, con su noción de existencia, abría la posibilidad de aprehender la estructura del modo particular de ser del hombre, posibilidad que no fue desaprovechada por psiquiatras como Binswanger quienes vieron, en su analítica, la vía para ofrecer un nuevo suelo o fundamento a la disciplina.

Así fue como el suizo obtuvo, de Heidegger, las herramientas necesarias para dar respuesta a sus preguntas sobre la concepción del ser humano y los elementos necesarios para la elaboración de su Análisis existencial. No obstante, por su condición médica, aspiraba -como venimos apuntando-a un análisis diferente del ser. A él le interesaba la historia vital del paciente, la vivencia concreta que de su mundo tuviese para, con ella, analizar en su seno la propia enfermedad en tanto un elemento más de su existencia. Dicho de otro modo, a Binswanger le interesaba conocer el Lebenswelt de sus pacientes, su mundo de la vida, tanto del neurótico como del esquizofrénico, tomados estrictamente en cuanto a lo que eran, vivencias, más allá de cualquier doctrina científica que actuase como prejuicio. En términos fenomenológicos diríamos que Binswanger, en su análisis de la existencia del paciente, pretendía comprender el modo en que este percibe o vive su mundo físico (Unwelt); el modo de relacionarse con sus prójimos (Mitwelt); y el mundo más personal e íntimo, su Eigenwelt ${ }^{11}$. Por esta necesidad de atender a cada paciente como una realidad única en cada caso, resultaba innegociable acercarse a él como a un ser total e íntegro en y por sí mismo, esto es, mediante una atención o cuidado libre de prejuicios y preconceptos, a saber, tras ejercer

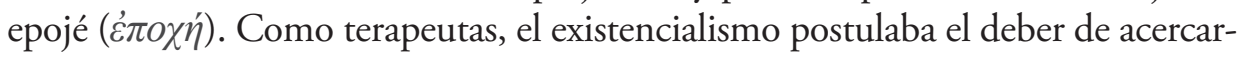
se al paciente habiendo realizado un género de $\dot{\pi} \pi o \chi \eta ́$ que venciese la ingenuidad de la mirada natural. Era necesario salvar todo tipo de prejuicios, proyecciones o generalidades $-\delta \delta^{\prime} \xi \alpha$ en general- que pudiesen conducir, en el terapeuta, a una distorsionada comprensión de la existencia de su paciente ${ }^{12}$. El terapeuta tenía, así, la responsabilidad de aproximarse a su paciente mediante una mirada fenomenológica, mediante una atención que aspirase a la intimidad o esencia de los fenómenos, a ese "volver a las cosas mismas", al paciente mismo. Binswanger, hasta entonces fiel al legado heideggeriano, reformuló su Daseinanalytik al pretender

${ }^{11}$ Cfr. BOEREE, G. op. cit., p. 9.

${ }^{12}$ En semejante intención hallamos a Rogers y su enfoque terapéutico centrado en la persona. Cfr. SASSENFELD, A. y L. MONCADA. (2006). "Fenomenología y psicoterapia humanista-existencial”. Revista de Psicología de la Universidad de Chile. Vol. XV/1, pp. 101 y sig. 
ese abordaje más centrado en cada paciente, en cada historia de vida, pues la aproximación ontológica, por su pretensión de universalidad, no se lo permitía. Ello le condujo a un modo de análisis más antropológico, un análisis empírico que tuviese en cuenta, no al existir sui generis, sino a las diversas maneras de existir. Binswanger buscaba aquello que Ferro Bayona $(2001,55)$ definía como "el desarrollo inmanente de la historia individual", de cada una de las historias de sus pacientes, pues en ellas se desarrolla su semiología, en ellas se despliega su malestar o desadaptación como un elemento más de su biografía, nunca fuera de ellas. Así comienza Binswanger a armonizar involuntariamente con las ideas orteguianas para quien las anomalías -decía Yela (1983, 239-240) - "no son, sin más, efectos automáticos y anónimos de tales o cuales causas" sino que son de la misma vida biográfica de cada uno, "no es algo adventicio que pueda o no padecerse. Se sufre siempre. La cuestión es con qué matiz, calidad y grado”.

Tener presente la biografía de cada paciente para comprender su patología implicaba, como decíamos, alcanzar su mundo de la vida, su Lebenswelt, lo que suponía tener en cuenta la estructura de ser-en-el-mundo como algo vivido por cada sujeto en cada caso. Decía Dörr (2008, 14), "a diferencia de Heidegger, Binswanger no concibe el ser-en-el-mundo solo como una estructura universal del hombre, sino como la unidad concreta de sí-mismo y mundo inherente a cada ser humano", noción que bien podría estar sacada de El hombre y la gente o de las Meditaciones del Quijote cuando Ortega definía a la circunstancia como "la otra mitad de mi persona" (OC, I, 756), especialmente cuando postulaba su idea de vida como única realidad radical diciendo:

Es, sencillamente, que la realidad primordial, el hecho de todos los hechos, el dato para el Universo, lo que me es dado... "mi vida" -no mi yo solo, no mi conciencia hermética, estas cosas son ya interpretaciones, la interpretación idealista. Me es dada "mi vida", y mi vida es ante todo un hallarme yo en el mundo (OC, VIII, 345).

Si bien la noción de "mi vida" tiene muchos paralelismos con la idea de "existencia" en Heidegger, si algo les diferencia es que Ortega nunca pierde de vista la circunstancia fenoménica de cada vivencia. Para Ortega nada humano va más allá de la historia, pues el hombre es histórico, donde cada cual tiene la responsabilidad de desplegar su propio proyecto de vida y que hace del mundo 
una realidad personal e intrasferible. No existe una naturaleza fija, una "existencia", lo que hay es vida, "mi vida" en cada caso.

No es difícil derivar de ello que Binswanger coincidiese también con Ortega en que "el lugar de la Psicopatología es la vida humana [...] la que cada Yo hace con su circunstancia" (Yela, 1983, 237), esto es, la patología entendida como un elemento no extrańo de la propia existencia, pues esta se da en el mismo existir, donde paciente -con su enfermedad- y mundo no son sino aspectos de una misma unidad sintética, la que conforma su existencia misma, su vida. Espacio, por cierto, donde lo otro no se agota en el mundo objetual, sino que en él, el otro, ocupará un lugar privilegiado. Binswanger apelaba, para ello, a la noción de horizonte común, un concepto fundamental para su trabajo de intervención terapéutica.

El suizo defendía que el establecimiento de la relación terapéutica se fundamenta en la construcción de un horizonte de encuentro, común, creado entre ambos, paciente y terapeuta; un horizonte al margen de cualquier tipo de precedentes o preconcepciones. En él, se establece el tablero de juego donde desplegar vivencias, donde entender y atender a la visión que el paciente mantiene de su propia existencia, sin proyecciones, sin inferencias o abstracciones por parte del terapeuta. Como dice Villegas $(1981,19)$, "el psicoterapeuta [...] ve en el enfermo una pareja existencial. Lo que enlaza a ambos es el encuentro. La existencia es también coexistencia [...] un 'nosotros'”. Es el terreno del tuyo, donde paciente y terapeuta pueden coexistir $y$, por tanto, trabajar:

Lo que une a ambos, paciente y terapeuta, no puede llamarse contacto psíquico, sino que debe llamarse encuentro en el abismo de la existencia, como dice Martin Buber, que está ónticamente en el mundo no solo como sí-mismo (selbst) sino también como coexistencia o trato con los demás hombres y como estar-con-el-otro o amor (Binswanger, 1954) ${ }^{13}$.

${ }^{13}$ En VILLEGAS, M. op. cit., p. 19. Citando a BINSWANGER, L. (1945). "Wahnsinn als lebengeschichtliches Phänomen und als Geisteskrankheit". Monatschr. f. Physch. und Neur. Vol. 10/3-4. 
También Ortega, "desde su antropología filosófico sociológica, extiende la fenomenología de las estructuras ontológicas de la vida humana como realidad radical al ámbito de lo social" (Haro Honrubia, 2010), al terreno del "nosotros". Bien es cierto que Ortega, debido a la particularidad e imposibilidad de transferir la perspectiva que todo sujeto obtiene de su mundo, habla de un vida vivida en radical soledad, de ahí que nuestras almas sean "astros mudos [que] ruedan las unas sobre las otras, pero siempre las unas fuera de las otras" (OC, VI, 211). Sin embargo, que nuestra perspectiva sea irrepetible e intransferible no significa que no sea almacenable ni comunicable, de modo que existe un atisbo de salvación condicionado percisamente a ese diálogo con el otro, en el "nosotros", pues es entre todos los hombres que podemos llegar a vivir lo humano ${ }^{14}$. Sin ese intercambio de perspectivas, sin esa construcción de lo social, estaríamos condenados al solipsismo más radical y al "aniquilamiento por desconexión”. Por ello, pese a la inevitabilidad de la soledad, apunta Ortega que hablar del hombre fuera de una sociedad, como ajeno, es algo por sí contradictorio y sin sentido aludiendo, en $E l$ hombre y la gente, a una especie de nostrismo o nostridad (cfr. OC, X, 208 y sig.). Esa nostridad es pareja a la idea del nosotros que agitaba el interés de Binswanger alejándolo de los postulados heideggerianos, pues, al suizo, más que la estructura de ser-en-el-mundo, le interesaba la de ser-en-el-mundo-con-el-otro: el ser-encomún. Y aquí anticipamos otra diferenciación radical respecto de Heidegger y que veremos a continuación: su idea del cuidado o Sorge que, según Binswanger, debía afectar también a ese otro y no solo a uno mismo.

\section{La idea del Liebe frente al Sorge}

Binswanger, en su tarea por conformar una teoría de la personalidad, estableció una estructuración antropológica basada en diferentes "tipos existenciales" 15 , tarea, por cierto, que recuerda mucho al intento orteguiano por estructurar o enumerar ciertas formas concretas de vida humana, lo que Julián Marías llamara la estructura empírica de la vida humana ${ }^{16}$-podemos recordar, así, las descripciones orteguianas del gentleman y del hidalgo, del

\footnotetext{
14 “'Solo entre todos los hombres llega a ser vivido lo humano' -dice Goethe” (OC, II, 163). 15 Cfr. BINSWANGER, L. (1955). "Das Raumproblem in der Psychopathologie" (1932). Ausgewählte Vorträge und Aufsätze. Band II. Bern: Francke Verlag.

${ }^{16}$ Cfr. MARÍAS, J. (1970). Antropología metafísica. La estructura empirica de la vida humana. Madrid: Revista de Occidente.
} 
bodhisattva, del hombre técnico o del hombre-masa ${ }^{17}$-. El caso de Binswanger, no obstante, al carecer de afán sociológico, se centró más en un conjunto de pares estructurales con los que recoger los distintos tipos de existencia que él mismo había compilado a lo largo de sus años de investigación empírica. Entre estos, por no despistar demasiado nuestros asuntos, podríamos citar, a modo de ejemplo, las dimensiones de arraigo/desarraigo, el hecho de referirse al pasado/ al futuro u orientarse a una meta/a la diversidad. Destacaremos, no obstante, un par que el mismo Binswanger consideró como el tipo de existencia auténtica o completa y que, precisamente, respondía a su intento de comprender al ser humano como un ser dialéctico o comunitario: hablamos del tipo dual-plural.

El par dual-plural se oponía frontalmente al modo de ser singular, habitual en toda teoría existencialista y muy presente en la visión heideggeriana, un modo de ser que el suizo consideraba antropológicamente deficiente dado su carácter autosuficiente y aislado ${ }^{18}$. Ya Ortega postularía que "la inconexión es el aniquilamiento" (OC, I, 749). Por su parte, a diferencia del singular, el par dual-plural enfatizaba ese "nosotros", ese estar-con-el-otro o ser-en-común que, para Binswanger, suponía la manera más elemental u originaria de existencia ${ }^{19}$, según él, el mundo, el horizonte, siempre se ofrecía compartido.

Partiendo de semejante giro, Binswanger se vio en la tesitura de revisar la noción heideggeriana del Sorge en tanto esta refería al modo o disposición de ser-en-el-mundo orientado al amor o cuidado que se mantiene hacia uno mismo, a la atenuación de "mis" preocupaciones arrastrando, con ello, un sentido trágico de la existencia. Para dicha revisión, cual buen terapeuta, yuxtapuso al Sorge el concepto de Liebe (amor) entendiendo a este como modo compensatorio de ocuparse del otro en sentido positivo, en un sentido plenario del "nosotros". Según él, corregía así la insuficiencia que presentaba el concepto heideggeriano de Sorge.

Contraponer el "ser-más-allá-del-mundo" como ser de la existencia, en razón de nosotros, designado por Heidegger como se sabe, como preocupación o Sorge, al "ser-más-allá-del-mundo" como ser de la existencia, en razón

${ }^{17} \mathrm{Cfr}$. Meditación de la técnica y La rebelión de las masas.

${ }^{18}$ Cfr. BONÉ, I. (2010). Vulnerabilidad y enfermedad mental: la imprescindible subjetividad en psicopatología. Madrid: Universidad Pontificia de Comillas, p. 130.

${ }_{19}$ Para un análisis fenomenológico del ser-con-el-otro, cfr. BINSWANGER, L. (1942). Grundformen und Erkenntnis menschlichen Daseins. Zürich: Max Niehans. 
de nosotros, designado por mí como amor [...] las transformaciones de la trascendencia en el sentido de la sobreexaltación del amor, mucho antes que las trasformaciones de la trascendencia en el sentido de la superación de las preocupaciones (Binswanger, 1973, 170-171).

Cierto es que, con el tiempo, Binswanger "rectificaría" o, más bien, matizaría su distanciamiento con la noción del Sorge al entender que ambos conceptos -el cuidado a uno mismo y cuidado hacia el otro- no eran contradictorios entre sí, más bien complementarios ${ }^{20}$. En esa línea trabajó Medard Boss, discípulo de Binswanger y también de Heidegger, quien interpretaría, en el germano, dos tipos de cuidado-por-el-otro, el que Heidegger refiere como "cuidado adelantado y liberador" (Vorspringende Fürsorge), una especie de anticipación a la ocupación, de pre-cuidado o pre-ocupación; y su einspringende Fürsorge, donde el otro toma mi lugar y me domina ${ }^{21}$. Para Boss, sería el primer tipo de cuidado, el de una atención adelantada y liberadora, el deseable en toda relación terapéutica, una matización que, de algún modo, volvería a armonizar a Heidegger con Binswanger al ofrecer un tipo común de cuidado hacia el otro en sentido propositivo. Como veremos, también acercaba a ambos a la idea orteguiana de la pre-ocupación, un término que, si bien se demuestra cercano al concepto Sorge -así lo reconoció el propio Ortega en su curso ¿Qué es filosofía? (cfr. OC, VII, 372)-, encaja aún mejor con el Liebe de los psiquiatras existencialistas, pues ofrece ese complemento que el mismo Ortega echaba en falta en la noción heideggeriana, la parte centrífuga, el elemento emprendedor o vitalista, amoroso, pues cuando Ortega habla de amor, siguiendo a Pfänder ${ }^{22}$, lo hace como ese "acto centrífugo del alma que va hacia el objeto en flujo constante y lo envuelve en cálida corroboración, uniéndonos a él y afirmando ejecutivamente su ser" (OC, V, 462). Cuando Ortega habla de amor, acentúa siempre esa tendencia que pretende convertir el espacio vital en espacio compartido, esa aproximación ontológica hacia el prójimo subrayando el poro que

${ }^{20}$ Como indica Boné, Binswanger reconocerá, en una carta escrita a Buber en 1936, su error al malinterpretar el Sorge heideggeriano como opuesto a lo relacional siendo ambos complementarios (cfr. BONÉ, I. op. cit., p.131n).

${ }^{21}$ Cfr. CAPURRO, R. (2003). "Análisis existencial y relación terapéutica: La influencia de Martin Heidegger en la obra de Ludwig Binswanger y Medard Boss". Revista Portuguesa de Filosofía. Vol. LIX/4, pp. 327-339.

22 PFÄNDER, A. (1913). "Zur Phänomenologie der Gesinnungen”. Jahrbuch für Philosophie und phänomenologische Forschung. Hale. 
permite al ser abrirse al mundo y tender hacia lo amado como a la búsqueda de una liberación, de una complacencia vital. Nada tiene que ver con el deseo, ni con la alegría ${ }^{23}$, ni es una pretensión de que el objeto venga a mí, todo lo contrario, "por el poro que ha abierto la flecha incitante del objeto brota el amor y se dirige activamente a este [...] del amante al amado [...] íntimamente de nuestro ser al prójimo" (OC, V, 460). Eso es el amor para Ortega: un empuje que hace que nuestra alma prorrumpa de nuestros adentros y se dirija hacia el objeto amado: "una fluencia, un chorro de materia anímica, un fluido que mana con continuidad" (OC, V, 460), una virtual corriente centrífuga que se dirige hacia lo otro amado.

\section{El Liebe y la preocupación}

La proximidad del Liebe existencialista con la idea de preocupación orteguiana la podemos ver desarrollada, de un modo aplicado, en el artículo "La percepción del prójimo". En este, Ortega despliega la idea de preocupación por el otro manifestando su repudia a los posibles apriorismos que se producen en la empresa de ir hacia cualquier alteridad (v. g. la Einfühlung scheleriana). El filósofo madrileño prefiere la prudencia en lo que refiere a las alteridades y, reafirmando la fenomenológica necesidad de ceñirse a "las cosas mismas", asumiendo en cada alteridad un enigma indescifrable desde nuestra situación, estima quedarse con el carácter problemático de acercarse al otro como si de un alter ego se tratase -visión defendida por quienes afirman la posibilidad de una estructura universal del hombre-. A ellos les critica, Ortega, el hecho de dar por sentado que uno se conozca suficientemente a sí mismo como para poder colegir que el otro se le asemeja, carencia promovida, simple y llanamente, por la limitación de nuestra capacidad atencional: no podemos percibir la totalidad de lo real, ni siquiera de lo real que hay en nosotros mismos, pues el hombre "no percibe en cada instante sino una mínima porción de él” (OC, VI, 218). Afirmar, pues, que podemos empatizar con el otro como si de nosotros mismos se tratase es, cuanto menos, problemático. Ello nos empuja a contemplar-desechada la vía del alter ego- la posibilidad de un "nosotros" como vía de acceso al otro, de un acceso dialéctico tal y como Binswanger apuntara. Decía Ortega: "la vida es una

${ }^{23}$ En su repaso histórico a los estudios sobre el amor, cita Ortega, entre otros, los errores de San Agustín al hacer del amor deseo y los de Spinoza al confundirlo con la alegría. Cfr. OC, $\mathrm{V}, 459$. 
constante preocupación y ocupación con las cosas que nos rodean, un dinámico diálogo con el contorno" (OC, VI, 213) del cual la "alteridad" es una pieza fundamental. Diálogo con el otro, con ese ente que, encerrado en su cuerpo y a modo de prójimo, se nos presenta compartiendo horizonte como otra mente que actúa independientemente de la mía, que percibo y, sin embargo, se me resiste:

No es el mundo único y objetivo quien hace posible que yo coexista con los otros hombres, sino, al revés, mi socialidad o relación con los otros hombres es quien hace posible la aparición entre ellos y yo de algo asi como un mundo común (OC, X, 208).

El otro, pues, al igual que el mundo en su conjunto, nos resulta tan problemático como necesario e ineludible, sobre todo si pretendemos un tipo de vida auténtico, pues, como mundo, también el otro me complementa y me conforma circunstancialmente. Así, en él y con él-como parte elemental de mi vida- actuamos e interactuamos en un quehacer constante, nos ocupamos de él, cuidamos de él. Afirmaba Ortega que "la vida es 'cuidado', cuidar-Sorge- lo que los latinos llaman cura, de donde viene procurar, curar, curiosidad, etcétera" (OC, VIII, 372). La vida es cuidar, pro-curar-por, "la vida es preocupación". No obstante, existe una diferencia fundamental entre el Sorge y su noción de preocupación: Ortega refiere a la preocupación y ocupación del sujeto en cuanto a decidir o inventar de su vida; sin embargo, Heidegger -como adalid de la filosofía existencialista- lo hace en cuanto a preocupación o angustia frente a la muerte. Como esgrimiese Cerezo Galán ${ }^{24}$, Ortega presenta la preocupación con aire deportivo (como un juego dramático), de un modo propositivo, mientras que Heidegger lo tiñe de otro más patético o pesimista, más trágico, debido a un encaramiento distinto de la muerte ${ }^{25}$. Es lo que el propio Ortega le recrimina a Heidegger y que tan bien armoniza con la visión binswangeriana: " $¿ L a$ vida como angustia, señor Heidegger? ¡Muy bien! Pero... además, la vida como empresa” (OC, IX, 541).

${ }^{24}$ Cfr. CEREZO GALÁN, P. (1984). La voluntad de aventura. Aproximamiento crítico al pensamiento de Ortega y Gasset. Barcelona: Ariel Filosofía.

${ }^{25}$ Cfr. MORÓN ARROYO, C. (1968). El sistema de Ortega y Gasset. Madrid: Alcalá, p. 187. 
Sin negar la sombra de la muerte, que a todos nos iguala (onmia mors equat), prefiere enfatizar Ortega el prendimiento del sujeto a la vida, lo que nos exige atender a cada individuo según su propio plan como ser en sí mismo, como un ser diferenciado, pues si la muerte nos iguala, la vida, por el contrario, nos diferencia. He aquí por lo que Ortega, como también sucediese en Binswanger, se decanta por un método de aproximación antropológico. Es la vida de cada cual -su propia existencia- la que le interesa, no la existencia en abstracto, no el ser en general del hombre. Ortega, y Binswanger, persigue asir aquello que diferencia a cada humano y lo hace auténtico; aquello que le orienta "hacia la realización de ese imperativo de perfección (entelequia) pindárico -llega a ser el que eres-, que para Ortega supone la vida auténtica”26. Decía San Martín $(1998,192)$, "la vida es ante todo darse cuenta, existir para sí misma, por tanto el ser nuestra, el ser a sí misma". Por ello no entendemos "vida" en un sentido meramente biológico como tanto recriminó Binswanger-, sino "vida" en cuanto mía, en cuanto vivida por mí, ejecutivamente, históricamente, biográficamente, "mi vida".

Ello aviva todo un alegato de responsabilidad y asunción de esa vida para con cada uno de nosotros, la obligación de llegar a ser lo que somos, de tomar conciencia y hacernos cargo de que nuestra vida es nuestra, incluso si manifiesta patología. Ni qué decir cabe que, en ella, el otro, la alteridad, en tanto coexistente con nosotros, también forma parte de la misma. Binswanger pretendía entender la existencia de sus pacientes como una unidad integral y diferenciada, donde la patología fuese un elemento más, donde sujeto y mundo se fundiesen en una noción más radical, la de ser-en-el-mundo, y en tanto humano, dada dicha coexistencia, con-otros. Por ello decimos que Binswanger se congrega con Ortega en tanto se diferencia de Heidegger por el camino de la antropología, pues a ambos, al filósofo raciovitalista y al terapeuta existencial, les preocupaba la alteridad en tanto elemento substancial de nuestra noción de ser humano, en tanto ser histórico y, por tanto, circunstancial. Desechar al otro, como excluir la enfermedad, supondrían tanto como perder el horizonte propiamente humano.

${ }^{26}$ GONZÁLEZ MORENO, F. y HARO HONRUBIA, A. (2004) "La estética de Ortega y el proceso de creación de un arte nacional”. Taula, quaderns de pensament, núm. 38, p. 235. 


\section{Conclusiones}

El presente artículo solo pretendía ser un breve acercamiento a las semejanzas halladas entre las teorías antropológicas orteguianas y el Análisis existencial de Binswanger. Como tal, se presta a un análisis mucho más profundo y sistemático del que aquí hayamos podido desplegar. No obstante, sí creemos haber conseguido evidenciar que la proximidad entre el pensamiento orteguiano y las ideas binswanguerianas aduce a algo más que a un mero encuentro fortuito: por un lado, estimulan los análisis sobre el papel que la fenomenología ejerce en Ortega; por otro, pone sobre la mesa, una vez más, las patentes disputas sobre la originalidad y el alcance de sus ideas frente a las de Heidegger.

Sobre la primera idea, el papel de la fenomenología en Ortega, no vamos a descubrir nada ${ }^{27}$. Solo destacaremos el hecho de que, cuanto más se deshilvanan los alcances del pensamiento orteguiano -especialmente de su metodología perspectivista- y cuantas más aplicaciones hallamos al método fenomenológico - debido a su fundamentación última en una teoría también perceptiva ${ }^{28}$ - más semejanzas parecen descubrirse entre ambos. El perspectivismo se fundamenta sobre el fenómeno de la atención ${ }^{29}$, lo que le depara muchas semejanzas con la teoría perceptiva de Husserl, desarrollada, entre otros, por Gurwitsch y MerleauPonty ${ }^{30}$ y alcanzando a la fenomenología existencial en su conjunto. Si el método se asemeja, la aplicabilidad del mismo de buen recaudo ofrecerá afines resultados. Otra de las explicaciones la hallamos, insoslayablemente, en lo pragmático del pensamiento orteguiano. Una de las mayores virtudes de su filosofía es la capacidad de aplicación al quehacer humano, por ello, cualquier intento fenomenológico de aplicación a este encontrará irremediablemente aspectos de su doctrina.

\footnotetext{
${ }^{27}$ Cfr. SAN MARTÍN. J. (1998). Fenomenología y cultura en Ortega. Ensayos de Interpretación. Madrid: Tecnos; y (2012). La fenomenología de Ortega y Gasset. Madrid: Ed. Biblioteca Nueva, colección el Arquero.

${ }^{28}$ Cfr. GURWITSCH, A. (1979). El campo de la conciencia. Un análisis fenomenológico. Madrid: Alianza.

${ }^{29}$ Cfr. CARPINTERO, H. (1990). “Ortega y la Psicología: el caso de la atención”. Revista de Occidente. Núm. 108, pp. 49-60; "AUTOR” (2015). “...."

${ }^{30}$ Cfr. GURWITSCH, A. op. cit.; MERLEAU-PONTY, M. (1985). Fenomenología de la percepción. Barcelona: Planeta de Agostini.
} 
Sobre la rivalidad histórica y reconocida con Heidegger ${ }^{31}$, el germano tuvo no pocos factores coyunturales a su favor. Nunca se aplicó mejor aquello de que "yo soy yo y mi circunstancia", pues la espańola y la germana en aquel tiempo marcaron mucho el devenir del pensamiento de ambos filósofos. Quizá también afectase a su reconocimiento el estilo de sus publicaciones, Ortega se dispersó, quizá demasiado, entre artículos e intentos de publicaciones nunca rematadas. Sin embargo, con el tiempo, la aplicabilidad de las doctrinas heideggerianas al campo de lo social, de lo antropológico, de la cotidianidad, están demostrando que ese predominio germánico fue más coyuntural que de fundamento, pues tematizaciones como la que acabamos de ver en este artículo evidencian que Ortega, más allá de anticipar o no ideas atribuidas genuinamente a Heidegger, en su aplicabilidad nunca le fue a la saga, sino todo lo contrario.

\section{Bibliografía}

Binswanger, L. (1942). Grundformen und Erkenntnis menschlichen Daseins. Zürich: Max Niehans.

(1945). "Wahnsinn als lebengeschichtliches Phänomen und als Geisteskrankheit". Monatschr. f. Physch. und Neur. Vol. 10/3-4.

(1955). "Das Raumproblem in der Psychopathologie" (1932). Ausgewählte Vorträge und Aufsätze. Band II. Bern: Francke Verlag.

(1973). "De la dirección analítico-existencial de la investigación en psiquiatría". Binswanger, Artículos y conferencias escogidas. Madrid: Gredos, pp. 166-190.

Binswanger, L. y Freud, S. (1995). Sigmund Freud-Ludwig Binswanger. Correspondance 1908-1938. En FICHTNER, G. (ed.). Paris: Calman-Levy.

Boeree, C. G. (2005). “Teorías de la personalidad. Ludwig Binswanger (1881-1966)”. Teoría de la Personalidad: una selección de los mejores autores del siglo XX. Sto. Domingo: UNIBÉ, pp. 1-12. Recuperado el 4 de marzo de 2015 de http://www. psicologia-online.com/ebooks/personalidad/binswanger.htm

BonÉ, I. (2010). Vulnerabilidad y enfermedad mental: la imprescindible subjetividad en psicopatologia. Madrid: Universidad Pontificia de Comillas.

${ }^{31}$ Sobre el ardor de las disputas entre Heidegger y Ortega, ver "Pidiendo un Goethe desde dentro" (OC, IV, 403n-404n). 
Capurro, R. (2003). "Análisis existencial y relación terapéutica: La influencia de Martin Heidegger en la obra de Ludwig Binswanger y Medard Boss". Revista Portuguesa de Filosofía. Vol. LIX/4, pp. 327-339.

Carpintero, H. (1990). “Ortega y la Psicología: el caso de la atención”. Revista de Occidente. Núm. 108, pp. 49-60.

Cerezo Galán, P. (1984). La voluntad de aventura. Aproximamiento crítico al pensamiento de Ortega y Gasset. Barcelona: Ariel Filosofía.

Dörr, O. (2008). "Los trastornos de personalidad desde una perspectiva fenomenológica”. Actas Españolas de Psiquiatría. Núm. 36/1, pp. 10-19. Recuperado el 4 de marzo de 2015 de http://actaspsiquiatria.es/repositorio/9/49/ESP/9-49ESP-10-19-774914.pdf

Ferro Bayona, J. (2001). "Filosofía y Psicología en el Análisis Existencial de Ludwig Binswanger”. Psicología desde el Caribe. Universidad del Norte. Núm. 7, pp. 47-59.

González Moreno, F. y Haro Honrubia, A. (2004) "La estética de Ortega y el proceso de creación de un arte nacional”. Taula, quaderns de pensament. Núm. 38, pp. 231-240.

Gurwitsch, A. (1979). El campo de la conciencia. Un análisis fenomenológico. Madrid: Alianza.

Haro Honrubia, A. (2010). "Antropología de los usos sociales como constitutivos de la 'gente'. Un estudio desde Ortega”. Gaceta de Antropología. 26/1. Recuperado el 4 de marzo de 2015 de http://www.ugr.es/ pwlac/G26_02Alejandro_DeHaro_Honrubia.html

Heidegger, M. (1929). "De la esencia del fundamento". Ser, Verdad y Fundamento. PsiKolibro. Recuperado el 4 de marzo de 2015 de http://es.scribd.com/ doc/23604852/Martin-Heidegger-Ser-Verdad-y-Fundamento\#scribd

(2009). Ser y tiempo. Madrid: Editorial Trotta.

Marías, J. (1970). Antropología metafísica. La estructura empírica de la vida humana. Madrid: Revista de Occidente.

Merleau-Ponty, M. (1985). Fenomenología de la percepción. Barcelona: Planeta de Agostini.

Morón Arroyo, C. (1968). El sistema de Ortega y Gasset. Madrid: Alcalá.

Ortega y Gasset, J. (2004-2010). Obras completas. Madrid: Taurus: Fundación Ortega y Gasset, Centro de Estudios Orteguianos.

PFänder, A. (1913). “Zur Phänomenologie der Gesinnungen”. Jahrbuch für Philosophie und phänomenologische Forschung. Hale. 
SAn martín, J. (1998). Fenomenología y cultura en Ortega. Ensayos de Interpretación. Madrid: Tecnos.

(2012). La fenomenología de Ortega y Gasset. Madrid: Ed. Biblioteca Nueva, colección el Arquero

Sassenfeld, A. y Moncada, L. (2006). "Fenomenología y psicoterapia humanistaexistencial". Revista de Psicología de la Universidad de Chile. Vol. XV/1, pp. 91-106.

SolÉ, S. (2011). "Lindes fenomenológicos de la psiquiatría existencial". Revista de la Asociación Española de Neuropsiquiatría. Núm. 31/112, pp. 647-660.

Villegas, M. (1981). "Ludwig Binswanger: En el centenario de su nacimiento". Anuario de Psicología. Núm. 24/1, pp. 5-26.

Yela, M. (1983). "Yo, mis circunstancias y sus anomalías". Psicopatología. "Ortega para la Psicopatología" II. Vol. 3/3, pp. 233-242.

Recibido: $17 / 03 / 2015$

Aceptado: 1/07/2015

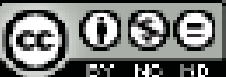

ENDOXA está bajo una licencia de Creative Commons Reconocimiento-NoComercial-SinObraDerivada 4.0 Internacional 
